\title{
Prophetic visions and the "Inner Self Helper"
}

To the Editor:

In the Fall 1988 issue of the Journal, Kenneth Ring (1988) discussed reasons why prophetic visions may not be accurate. I believe I can supply information that shows why prophetic visions may be incorrect; this explanation also relates to Michael Grosso's (1985) concept of Mind-at-Large as described in the book review by Gordon Green (1988) in the same issue. In addition, my explanation also ponders a possible evolutionary path alluded to by Ring and Grosso.

My explanation is primarily a spiritual one, which speculates on the nature of a spirit form that inhabits the physical body and departs at death, or that is joined at death. Some preliminary information is a presentation of the concepts of Max Freedom Long (1948), who studied the "magic" of the kahunas among the native Polynesians in Hawaii. Long believed he discerned how the kahunas were able to perform their magic by understanding the tripartite spiritual nature of man. The Hawaiian names for these three spirits are Unihipili, Uhane, and Aumakua, but he called them simply low self, middle self, and high self.

Long believed the low self spirit had roughly the same size and shape as the physical body and resided in it. The middle self spirit was focused in the head/brain, while the high self spirit had a connecting cord to the physical body but did not penetrate it. The middle self, or normal waking consciousness, does not contact the high self, or superconsciousness, except through the low self, or nonrational subconscious; and even that contact is rare during waking consciousness without training in the manner of the kahunas.

Many of the phenomena encountered in the transcendental realm of a near-death experience (NDE) can be accounted for by speculating that the NDEr makes contact with the high self. According to Long, the high self, when properly requested, could perform miraculous heal- 
ings, control weather, and contact other high selves and spirit beings higher than itself. This spirit did not depart the body except at true death, often manifested as light, and cared for the other selves and for the physical body. It was composed of a male/female pair, and thus could demonstrate qualities of either gender. The high self did not think in the human sense, but simply knew.

Finally, the spirit could see into the future, but only the future that was "crystallized." The high self created the future of the individual from the thoughts that reached it. If necessary, the kahunas could rearrange the future of an individual by working with the person's high self. Presumably, the future of a society could be created from the thoughts or actions of many members of that society.

I believe the inaccuracy of NDErs' visions could be explained by this principle. At the time NDErs had their visions, perhaps five to ten years before 1988, a catastrophic scenario was the crystallized future. During the intervening years, various peoples' prayers and positive acts alleviated some of these consequences. Grosso mentioned visions of the Blessed Virgin and messages she has given. The Virgin at Medjugorje has stated that some of her earlier dire predictions did not occur because of peoples' prayers in the interim. Some predictions, however, are so crystallized that they supposedly cannot be averted.

Long also cautioned that the information from the high self is received through the nonrational low self. If the low self has not received information from the high self, it will create an answer, frequently what the requester desires to hear. This low self confusion is unlikely to occur during the NDE itself and is unlikely to produce the same prediction in several individuals, but it could occur in individualized visions that develop as a result of the NDE.

Although 1988 was not as disastrous as some NDErs predicted, at least in terms of earthquakes and war, it was considered an environmentally disastrous year in the form of drought. Perhaps the consequences of peoples' negativity were shifted to a milder form.

Another finding in recent years that seems to relate to a Mind-atLarge and NDE phenomena is that of the "Inner Self Helper" (ISH). This is a phenomenon discovered by therapists who treat patients with multiple personality disorder. Some therapists have found a "personality" that will assist the therapist in treating the patient by prioritizing the problems to be handled at that time, assisting in preventing suicide, producing customized dreams for the patient, and by other contributions to the therapy process.

There can be other helper personalities, but the ISH is distinctly different. Some therapists believe it is essential to the therapy process 
to find the ISH. The preferred method for employing the ISH is to have the patient develop the ability to ask the ISH questions, rather than the therapist's calling upon it in a manner similar to asking for other personalities. Some therapists believe that normal people also have an ISH. I suggest that they are correct, and that the ISH is also the high self and responsible for many of the parapsychological phenomena in NDEs.

The ISH is the only personality that knows of the existence of all the other personalities, including their histories. It is described as nonemotional and, by several therapists, as asexual. The ISH does not usually claim a name, but is assigned one by the patient or therapist. One ISH said that it is the source of love and artistic talent in the individual. One therapist conducted a survey of other therapists who have encountered the ISH in their therapy. Descriptions elicited in this survey included terms such as hyperintellectual and inhuman, one's own spirit or soul, aspects of the spirit of God, and a part of the patient's unconscious that is in touch with even Higher Helpers.

Another therapist believed that a patient's ISH telepathically contacted the therapist's ISH with a message. Other parapsychological and religious phenomena are sometimes associated with the ISH. One therapist stated that the ISH can accelerate healing and change the ages of the alternate personalities. The ISH claims that it can see into the future, although no instances of correct predictions have been published. Most predictions probably deal with the individual patient rather than world visions.

What seems to relate the ISH the NDEs? Christine Comstock (1987) has written extensively about her findings on the ISH. She has found that the first encounter with the ISH is very emotional and brings joy, peace, or a feeling of love. One patient described the voice of her ISH as the most beautiful she had ever heard. I believe the ISH is a functional and healing aspect of the high self, rather than inspirational or providing knowledge as in NDEs.

Finally, an evolutionary aspect can be inferred from these findings by further analysis of Long's description of the spirits of man. Conceivably, NDEs, the ISH, and related phenomena may be the result of the high self spirit's "incarnating" further into the physical body. Perhaps in the more primitive Polynesian society, the high self spirit was only attached to the physical body, but over a period of many generations it penetrates the physical body to a greater extent. This penetration may be gradual as a species, but it can also occur in spurts, such as in an NDE. However, the NDE could also be envisioned as the lower and/or middle self's leaving the body and joining the high self. 


\section{References}

Comstock, C. (1987). Internal self helpers or centers. Integration, 3(1), 3-12.

Greene, G. (1988). Book review of The final choice: Playing the survival game, by M. Grosso. Journal of Near-Death Studies, 7, 44-54.

Grosso, M. (1985). The final choice: Playing the survival game. Walpole, NH: Stillpoint Press.

Long, M. F. (1948). The secret science behind miracles. Santa Monica, CA: DeVorss.

Ring, K. (1988). Prophetic visions in 1988: A critical reappraisal. Journal of Near-Death Studies, 7, 4-18.

Dan Punzak

815 Randolph Court

Springfield, IL 62702 